\title{
Evaluation of the spatial and economic effectiveness of industrial land policies in Northwest Europe
}

\author{
Marie-Carline Vandermeer* \& Jean-Marie Halleux**
}

This version: 1 March 2017

* Lepur, University of Liège, Liège, Belgium

** ECOGEO, Department of Geography, University of Liège, Liège, Belgium

Marie-Caroline Vandermeer, ECOGEO, Department of Geography, University of Liège, 3 Clos Mercator, B11, 4000 Liège, Belgium. Tel: +32 4366 5747. Email: mc.vandermeer@ulg.ac.be

Jean-Marie Halleux, ECOGEO, Department of Geography, University of Liège, 3 Clos Mercator, B11, 4000 Liège, Belgium. Tel: +32 4366 5327. Email: jeanmarie.halleux@ulg.ac.be

Corresponding author: Jean-Marie Halleux, ECOGEO, Department of Geography, University of Liège, 3 Clos Mercator, B11, 4000 Liège, Belgium. Tel: +32 43665327. Email: jean-marie.halleux@ulg.ac.be

\section{Acknowledgments}

It was possible to carry out the research for this paper thanks to a research grant from the Walloon Region (Belgium) through the CPDT (Standing Conference on Territorial Development). The authors would like to thank Marcus Dejardin from the University of Namur as well as Bernadette Mérenne-Schoumaker from the University of Liège, whose valuable advice helped to develop the research. Thanks are also due to the anonymous reviewers for their richly detailed comments. 


\title{
Evaluation of the spatial and economic effectiveness of industrial land policies in Northwest Europe
}

\begin{abstract}
This article stems from the discrepancy between the lack of attention paid to industrial land policy by academics and the predominant thought among elected representatives and development agencies, i.e. that industrial land policy plays a key role in the creation of growth and new jobs. The article begins with a reflection on the literature, which stresses the need to develop knowledge on industrial land policies. To help fill this research gap, we have developed an exploratory piece of research on the theme of their spatial and economic effectiveness, on the basis of statistical analyses dedicated to seven countries. As regards spatial effectiveness, the results underline significant national differentials in terms of land consumption on the one hand, while highlighting the economic sprawl that affects France and Belgium on the other hand. As regards economic effectiveness, our results show that the impact of the development of economic estates on growth depends largely on regional contexts. In particular, the "intermediate regions" in western Germany stand out as belonging to a specific context where land policies seem particularly effective from an economic standpoint. By contrast, the economic effectiveness of industrial land policies requires readjustments in most "predominantly rural regions, close to a city".
\end{abstract}

\section{Keywords}

Regional development, land policy, economic estates, industrial land, land consumption, spatial effectiveness, economic effectiveness

\section{Introduction}

The involvement of public authorities is clearly present in the domain of land for industrial developments: "they publish information (make the market more efficient), assemble difficult sites, buy from 'passive owners', remove physical constraints, and so on" (Needham, 1995, p. 464). In several European countries, the involvement of public authorities in industrial land policy goes as far as the public development of economic estates, i.e. land specifically developed to accommodate economic activities. For instance, these developments are common in France (Margary, 2012), Belgium (Vandermeer \& Halleux, 2013), the Netherlands (Ploegmakers et al., 2013) and Scotland (Bramley \& Kirk, 2005).

For local elected representatives and economic development agencies, industrial land policy is often considered as an essential factor in territorial competiveness and attractiveness. This predominant thought originates from a fear of losing local or regional firms due to a shortage in land supply. At the same time, this thought is also fuelled by the argument that the release of new land - cheap, if possible - will help to attract new investments from outside the regional territory. The research synthesised in this article originates from the discrepancy between this way of thinking and the scientific literature devoted to regional development. Indeed, unlike local stakeholders, scholars active in the field of regional sciences only very rarely refer to the impact of the land markets on levels of competitiveness and attractiveness. Rather than focusing on the theme of land and property, regional scientists underline the importance of intangible factors such as innovation, entrepreneurship, education, etc. (Martin, 2003).

Today, there is an abundance of literature on the intangible factors of regional development briefly listed above (innovation, entrepreneurship, education, etc.). On the other hand, the existing literature on the research theme of land and property in economic development remains limited and poor on a general level, despite its relative popularity in the nineties (Adams et al., 1994; Baker, 1995). In an effort to fill this 
research gap, we have developed an exploratory piece of research on the theme of the effectiveness of industrial land policies, with the aim to define their true roles in relation to economic development. As we will explain in further detail in the subsection 3.1, our theoretical framework is based on the differentiation between the spatial effectiveness on the one hand, and the economic effectiveness on the other. Our empirical analyses have been developed on the basis of a study area covering seven countries: Belgium, France, Germany, Ireland, Luxembourg, the Netherlands and the United Kingdom. We decided to work on this group of countries from Northwest Europe because there are many diversities in their industrial land policies, even though they belong to a relatively homogenous economic context.

The rest of the article is structured as follows. In section 2, we develop a reflection on the literature devoted to links between regional development and the commercial property market. This reflection aims to explain the limited availability of research on the links between regional development and land policies. The third section is devoted to the presentation of our theoretical framework as well as to the description of the methodological choices made for our statistical analyses. Here we present the data used and we deal with questions regarding the area of analysis, the scale of the data processing and the methods of operation mobilised to address the issues of spatial and economic effectiveness. The fourth and fifth sections are respectively devoted to statistical analyses on spatial effectiveness and economic effectiveness. Section 6 concludes the analysis and evaluates the main policy and research implications of our empirical findings.

\section{Why this lack of interest in the relationships between regional development and the isssue of land for industrial development?}

As mentioned in the introduction, the research theme of land and property in economic development remains limited. In order to understand this situation, it is useful to detail three main elements:

(1) the limited interest of regional scientists in the land issue,

(2) the focus of the urban economy on the intra-urban scale and,

(3) research on the economic impact of planning is still in its early stages.

\subsection{The limited interest of regional scientists in the land issue}

As previously mentioned, regional development practitioners pay great attention to the factor of the availability of industrial land. However, researchers who are active in the field of regional science only consider this factor to a limited extent (Halbert et al., 2014). D'Arcy and Keogh (1999, p.925) help explain this dichotomy by emphasising the fact that the literature on economic development generally considers that the land and property supply is supposed to react immediately to evolutions in demand. In other words, location markets are not supposed to hamper development as they are supposed to operate fairly and effectively. However, all the property and planning specialists know that land and property markets are far from being completely efficient in matching supply and demand (Adams et al., 1994, van der Krabben \& Buitelaar, 2010; van der Krabben \& van Dinteren, 2010).

In order to explain the very relative interest of regional scientists regarding the land issue, we should also emphasise the predominance of the knowledge-based economy paradigm. We shall illustrate this observation by referring to the typology of competitive regions established by Martin (2003). In this typology, which differentiates three groups of regions, land as an input factor in the economy is only taken into 
consideration for the first group: the "regions as production sites". Regions that draw their competitiveness from the low cost of production factors (labour, capital, land) are integrated into this group. Regarding the other two groups, which represent more economically evolved regions (the "regions as sources of increasing returns" and the "regions as hubs of knowledge"), the land problem is overlooked and the emphasis is placed on innovation and agglomeration economies.

The concept of agglomeration economies has become central in the field of regional development. This results from the fact that it provides an understanding of the apparently paradoxical situation of contemporary economies where the new organisation of the economy (globalisation) is accompanied, at the same time, by the decreasing importance of distance and the concentration of productive activity in the main metropolitan regions (metropolisation) (Rigg et al., 2009). Agglomeration economies can be divided into three major categories (see, for instance, Fujita \& Thisse, 2000). Firstly, there are the externalities linked to the presence of suppliers and customers, as it is generally in the best interest of firms to be located close to activities upstream and downstream of the production chain. Secondly, labour market pooling is another very powerful externality, stemming from the fact that the amount and the diversity of the employment offered in large employment areas increase the chances of matching labour supply and demand. Thirdly, information externalities, which result from knowledge transfer between conglomerate firms, also act in favour of the spatial concentration of businesses. Of course, besides agglomeration economies, we also find agglomeration diseconomies, ranging from traffic congestion and density-related pollution to pecuniary diseconomies such as high wages or high land costs.

The literature linking commercial property and regional development from the point of view of agglomeration economies and diseconomies reveals two types of approach, each with a very different conclusion in terms of the level of spatial concentration of firms. The first type, which is intuitively the easiest to grasp, relates to the impact of the competition on land in highly sought-after urban locations. Due to this competition, we see both a scarcity of the offer and a price rise on the markets. As regards firms, the issue here is pecuniary agglomeration diseconomy, as high land and property prices might affect their profitability - and even their competitiveness - owing to the impact on their production costs. The direct consequence is the spatial dispersal of land hungry industries. To complete the theoretical reasoning, we have to keep in mind that high land and property values usually represent the capitalisation of agglomeration economies, an observation that illustrates the intrinsic tensions between agglomeration economies and diseconomies when firms take a decision on their locational trade-offs.

Within the scope of agglomeration economies, the second type of approach that links commercial property to regional development relates to the efficiency of property markets in allowing businesses to limit their transaction costs when they have to adapt their locations. This subject has resulted in research mainly devoted to office markets (D'Arcy \& Keogh, 1997, 1999). Since it is office buildings that represent the physical structures of relational and informational resources, this interest in office space is indisputably the reflection of the dominant economic dynamics, where growth in developed countries is increasingly dependent on intangible elements linked to competences and innovation. The issue here is the agglomeration economy because, compared with second-rank cities, the highly structured and professionalised character of office markets in main metropolitan regions contributes to an increase in their attractiveness and, therefore, to the spatial concentration of economic life (Theurillat et al., 2014). 


\subsection{The focus of the urban economy on the intra-urban scale}

As we pointed out above, high land values should be considered as agglomeration diseconomies or, in other words, as a source of the spatial dispersal of the economic agents. For firms, the underlying economic reason is that high land and property prices are synonymous of high land and property costs. From this point of view, it is necessary to develop a multiscalar reflection in order to detail the impact of land prices on companies' property costs and on their location choices. In an effort to clarify this subject, it is necessary to distinguish the intra-urban scale on the one hand, and the inter-urban, inter-regional and international scales on the other. In scientific literature, the relationships between land markets and choice of location are usually associated with the intra-urban scale rather than with the aforementioned higher scales. In order to support this observation, we can refer to the field of spatial economics, where the issue of land rent is taken into consideration to explain a firm's location at the intra-urban scale. According to the foundational models of urban economics, location choices are explained according to the trade-off between land costs on the one hand, and distancerelated costs (especially transport costs) on the other hand (Alonso, 1964; Muth, 1969). The main prediction of these models is the structuring of urban regions through a decreasing gradient of land rent according to the distance from the city centre. The initial versions of these models only concern residential locations. However, as illustrated in the work of Costes (2008), they can easily be adapted to the location of businesses. On this basis, it is easy to differentiate between the location of offices in centres, where businesses that make the most of agglomeration economies are situated, and the expulsion of land-hungry businesses to peripheral locations.

The formalisation of the role of land rent on intra-urban locations has no equivalent on inter-urban or inter-regional scales. Urban economics therefore tend to consider land rent as a key determining factor in the choice of location on an intra-urban scale, but not as a key determining factor in the trade-off of businesses when they have to choose between different towns, different regions or different countries.

\subsection{Research on the economic impact of planning is still in its early stages}

The previous points reveal that specialists in regional sciences and urban economics are only marginally interested in the relationships between land markets and regional development. To have a complete view of the research devoted to this theme, we must also consider the work dedicated to the impact of planning practices. Some British works have focused on the relationship between the rigour of planners and businesses' property costs, like the model that Cheshire and Hilber (2008) calibrated in order to assess the impact of planning constraints on office development costs. They arrive at the conclusion that the restrictive policies in the United Kingdom impose additional costs amounting to $250 \%$ in Birmingham and between 400 and $800 \%$ in London. In comparison, additional costs are only 50\% in New York, 300\% in Paris and 200\% in Amsterdam.

For Cheshire et al. (2012, p.7), the additional costs observed in British cities should result in a reduction in investments. The underlying economic rationale is that, "all other things being equal", an area where land costs are higher will be less attractive than an area where land costs are lower. However, unlike the causal link between the rigour of planning and property costs, the causal link between costs and attractiveness is not dealt with by Cheshire and his colleagues. In order to support this hypothesis, it would be necessary to check whether these higher costs are not counterbalanced by other benefits (agglomeration economies) likely to generate proportionally greater gains in 
added value. Furthermore, it would also be necessary to assess the effective impact of property costs by comparing them to all the costs borne by businesses. From this perspective, even if we know little about company property costs, we can reasonably assume that they are generally minimal compared to wage costs (Needham \& Louw, 2006, p.88).

Henneberry et al. (2005) also focused on the impact of planning regulations on development costs. Their work integrated industrial property and sought to quantify the impact in terms of economic growth. The multiple equation models prepared by Henneberry and his colleagues (2005) show that a 10\% increase in planning permission leads to a $1.55 \%$ increase in local economic activity in office-based services, and $3.8 \%$ for firms based in buildings traded on the industrial property markets. The text presented by Henneberry et al. does, however, mention the methodological weaknesses and uncertainties concerning the results obtained: "our findings need much qualification. This was an initial analysis constrained by significant data limitations" (p. 122).

Ultimately, our review of the literature reveals that the link between land markets and regional development still has not been dealt with satisfactorily by research. As regards the potential links between land issues and companies' choice of location, the relation is clear within urban regions. On the other hand, once we depart from the intraurban scale, current knowledge does not help to objectivise the hypothesis according to which differentials in land availability and land price are likely to cause differentials in competitiveness and attractiveness. Although a number of works published by planning scholars deal with the impact of planning policies on companies' property costs, these works are still in their infancy and much remains to be done to objectivise the consequences of planning policies on the profitability of companies and, more broadly, on territorial competitiveness and attractiveness.

\section{Theoretical and methodological framework}

As highlighted in the previous section, there has been little research on the links between regional development and the issue of industrial land. In an effort to shed light on these complex relationships, we elaborated statistical analyses in order to develop an exploratory piece of research on the theme of the spatial and economic effectiveness of industrial land policies. The following explains the theoretical and methodological framework of these analyses.

\subsection{The spatial and economic effectiveness of industrial land policies: a theoretical framework}

The analyses were conducted with an aim to provide answers to the two following questions: i) "How different are the statuses of the countries in terms of economic land consumption?" and ii) "Is there any link between economic land consumption and the level of regional development?". The first question is related to the issue of the spatial effectiveness of industrial land policy. More specifically, it addresses the planning objective which consists of limiting the consumption of land for urbanisation (economic urbanisation in this case). The second question answers the issue of the economic effectiveness of industrial land policies. By answering the latter question, we should be able to justify the premise of many development practitioners according to which generous land supply represents a real asset for regional development.

To discuss the issue of spatial effectiveness, we elaborated a ratio in which the numerator measures the consumption of economic land and the denominator reflects the 
production of wealth. It was thereby possible to compare the countries based on the working hypothesis according to which, the lower the ratio, the higher the spatial effectiveness is. Here we drew inspiration from the approach on land productivity applied by Louw et al. (2012) to the Netherlands, by generalising it to the whole area of analysis.

With regard to the analyses on economic effectiveness, land consumption was correlated with GDP and employment numbers. Given this framework, our working hypothesis is that the land policies are all more effective when there is a high correlation between the level of development and consumption of industrial land. Indeed, a high correlation can be interpreted as a sign of the economic usefulness of land consumption.

In order to clarify the difference between spatial effectiveness on the one hand and economic effectiveness on the other, we can use the case of the Netherlands. As discussed later in detail, what we see in this country is a combination of good spatial effectiveness and poor economic effectiveness. While good spatial effectiveness is a consequence of a strong job density within economic estates, poor economic effectiveness results from the fact that the creation or the extension of economic estates does not significantly stimulate the regional economy.

The methodological choice to complete the evaluation of economic effectiveness through evaluating spatial effectiveness is justified by the fact that the industrial land policies can increase urban sprawl (van der Krabben \& Buitelaar, 2010) and, therefore, aggravate the well-known negative spatial impacts caused by it (EEA, 2006). The urban sprawl of economic activities is especially problematic when out-of-town economic estates are a host for businesses whose characteristics - low level nuisance for the neighbourhood and a large number of jobs per unit of area - would have been perfectly suited to inner city neighbourhoods. This is something we see in Wallonia for instance, where almost $50 \%$ of businesses and $20 \%$ of jobs located within out-of-town economic estates would have been perfectly suited to urban centres (Deloitte \& Touche et al., 2002, p.20). Situations like this are spatially ineffective as they exacerbate urban sprawl as well as vehicle traffic while also contributing unnecessarily to the devitalisation of traditional urban fabrics.

\subsection{The area of analysis and the scale of data analysis}

The area covered by our analyses includes seven countries: Belgium, France, Germany, Ireland, Luxembourg, the Netherlands, and the United Kingdom. The data analysis was carried out at the scale of the NUTS 3 regions. This is the most detailed level for which statistical data are available and comparable for the countries studied. The seven countries studied include 751 NUTS 3 regions.

Our approach has combined two levels of analysis: on the one hand, that of the whole of the territory studied and, on the other hand, that of the seven countries composing it. The countrywide analysis is justified by the national diversities relating to both economic specialisations and planning and development policies. Concerning planning policies, a differentiation has to be made between countries such as Belgium or France, where planning policies regarding the parsimonious use of land are relatively recent, and countries like Germany, the Netherlands and the United Kingdom, which can be considered as European pioneers in terms of planning policies and sprawl limitation (Halleux et al., 2012; Sellers, 2004). We also distinguished an intra-national level for Germany. This distinction turned out to be necessary considering the significant economic and spatial disparities that still exist between former East Germany and the rest of the country. 
As well as differentiation per country, we also made a distinction between the NUTS 3 regions according to their degree of urbanisation. This differentiation was taken into account on the assumption that the urban phenomenon determines the availability of land as well as the relationship between this availability and the level of development. The regions were classified according to the urban-rural typology including remoteness (European Commission, 2010). This typology identifies five NUTS 3 categories: "predominantly urban regions", "intermediate regions, close to a city", "intermediate, remote regions", "predominantly rural regions, close to a city" and "predominantly rural, remote regions". Map 1 represents the typology of the 751 NUTS 3 regions of the countries taken into account. For these countries, the number of "intermediate, remote regions" is very small (three regions). Consequently, our analyses only studied a single group for the so-called "intermediate regions".

Map 1. The NUTS 3 regions according to the urban-rural typology including remoteness.

\subsection{The data used}

For land consumption, we used the Corine Land Cover (CLC) data, which has the advantage of covering the whole area of analysis. The most recent available data was used, i.e. data from 2006. CLC data were produced by photo interpretation of satellite images. The final result takes the form of a land cover vectorial database, composed of polygons representing homogenous zones greater than 25 hectares and more than 100 metres wide. The CLC data distinguish five major types of land use: artificial surfaces, agricultural areas, forests and semi-natural areas, wetlands and water bodies. There are eleven categories within the artificial surfaces. For our analysis, we favoured the data relating to "industrial and commercial units". For greater simplicity, we renamed them "economic surfaces" (ES). These areas mainly correspond to economic estates. Moreover, we used data relating to the "continuous urban fabric" and "discontinuous urban fabric" categories. This is land mainly for residential purposes. In the rest of the article, we shall therefore use the term "residential surfaces" (RS) to refer to these landuse categories. Coordinated by the European Environment Agency (EEA), CLC data have the advantage of allowing a comparison on a European scale. The disadvantage is that they do not identify small economic estates of less than 25 hectares. In most European regions, however, it is unlikely that these small economic estates represent a significant proportion of economic surfaces.

For the level of development, we used two indicators: the purchasing power parity GDP and employment numbers in the secondary and tertiary sectors. The GDP and employment data at the scale of the NUTS 3 regions were directly extracted from the Eurostat website. We chose to extract 2006 data in order to use economic information relating to the specific period for which the land use information is available. Concerning the scale of data on GDP and employment, Eurostat does not provide information at a finer scale than NUTS 3. Therefore, it is not possible to associate the development indicators with well-defined economic estates relating to the polygons of the CLC vectorial database.

All in all, although our methods of operation described below are limited by the available sources of data, we nevertheless consider that they are sufficiently robust to achieve our fundamental objective, i.e. evaluating the spatial and economic effectiveness of industrial land policies.

\subsection{The methods of operation}


Our method of operation on spatial effectiveness is based on a comparative analysis relating to the consumption of economic land (section 4). This was performed according to a ratio where the consumption of land is divided by the production of wealth. This variable, which is expressed in hectares of economic surfaces per EUR 100 million of GDP, has been called the "GDP standard of the economic surfaces". In addition to the "GDP standard of the economic surfaces", we also calculated and analysed the GDP standards of the "residential surfaces", on the basis of a ratio where the numerator measures the consumption of residential land. As previously mentioned, our working hypothesis was that the lower the "GDP standard of the economic surfaces", the higher the spatial effectiveness.

As regards the relationships between economic land consumption and the regions' level of development (section 5), i.e. the economic effectiveness, we used the statistical tools of correlation and simple regression. These tools aimed to check whether, statistically speaking, economic land consumption helps to explain the levels of GDP and employment numbers. The correlation and regression analyses between the quantities of economic land and the levels of development aim to assess the economic effectiveness of the land policies and to verify the hypothesis according to which economic development is positively influenced by land consumption. From this point of view, it is necessary, statistically speaking, to control the size effect which results from the fact that the size of the regions influences both the quantities of economic land and the quantities of GDP and employment. If this effect was not controlled, the size differences between the regions would have an upward impact on the levels of correlation. In order to control this size effect, we divided the initial variables by the number of inhabitants.

\section{Spatial effectiveness: comparative study of economic land consumption}

Map 2 represents the GDP standards of economic surfaces, i.e. the indicator resulting from the division of the number of hectares of economic surfaces by the production of wealth expressed in EUR 100 million of GDP (2006 data). Table 1, which synthesises the data at a countrywide level, helps to complete the information provided by Map 2.

The comparison of national means identifies two countries that consume considerably more economic surfaces than the others - the production of wealth being equal. They are France and Belgium, with 19.3 ha and 16.6 ha respectively per EUR 100 million of GDP. In comparison, Germany and the Netherlands have averages that are similar to the overall average of the area of analysis (13.9 hectares). Finally, the three countries that appear to consume the least economic surfaces are the United Kingdom, Luxembourg and Ireland. Per EUR 100 million of GDP, their average consumptions are 9.0 ha, 8.1 ha and 5.4 ha respectively.

Besides land policies, it is necessary to include the factor of the countries' economic specialisations in order to interpret these results. The figures relating to Luxembourg, Ireland and the United Kingdom should be linked to these countries' specialisation in tertiary activities with high added values, such as the banking and finance sector (OECD, 2012). In order to explain the situation in the United Kingdom, we must also refer to the very strict planning policies that characterise this country, both as regards residential developments and economic developments (Henneberry et al., 2005).

Concerning France and Belgium, the extent of the GDP standards bears witness to land policies that pose a certain number of problems from a spatial point of view. This is a result that confirms several studies on the "economic sprawl" of services and companies that characterises both France (Demazière, 2014; Margary, 2012) and 
Belgium (Vandermeer \& Halleux, 2013). Among these problems is the fact that businesses and services adapted to urban locations - especially retail - are often being located in peripheral economic estates. Another problem relates to the low density of employment in these economic estates. For instance, as regards the situation in Wallonia, the density there is only 17 jobs per hectare. In comparison, the same indicator is 46 jobs per hectare for Dutch economic estates (Lambotte et al., 2010, p.3).

Map 2. The GDP standards of economic surfaces (2006).

Table 1. Average consumption of economic surfaces to produce EUR 100 million of GDP, standard deviation and coefficient of variation in 2006.

Table 1 also shows that the averages per country hide major intra-national disparities. Germany is the country with the greatest differences, with a clear split between East Germany and the rest of the country. This clearly emphasises how far behind former East Germany is in terms of economic development. The United Kingdom also has a high coefficient of variation (0.98). This can be explained by the situation of certain Scottish counties, where development is lagging behind and where development agencies have produced an oversupply of economic land (Bramley \& Kirk, 2005). On the other hand, France and Ireland are relatively homogenous countries, with coefficients of variation under 0.40. Finally, Belgium and the Netherlands occupy an intermediate position.

Map 3 represents the GDP standards of residential surfaces. In comparison with the GDP standards of economic surfaces, several elements deserve to be highlighted. First of all, the division between eastern and western Germany, although visible on the two maps, is far more noticeable in terms of the GDP standards of economic surfaces. Considering the legacy of the Communist period, it makes sense that the territories in former East Germany are characterised by a more extensive use of economic land than residential land. Indeed, the ideology that influenced town planning practices during the Communist period has led to the concentration of populations in apartment buildings on the one hand, and to the use of vast tracts of land to ensure the success of industry on the other (Halleux et al., 2012).

Map 3. The GDP standards of residential surfaces (2006).

Concerning Map 3, a second observation relates to Belgium and its North-South divide. For an equivalent production of wealth, Wallonia consumes nearly twice as many residential surfaces as Flanders, while there is almost no differential in terms of economic surfaces. This observation tends to underline a major problem of residential sprawl in Wallonia.

The specificity of certain Scottish counties, identified on the map representing the GDP standards of economic surfaces, does not appear on the map of GDP standards of residential surfaces. This situation would suggest that Scottish planners are more successful in managing residential land than economic land. The work of Bramley and Kirk (2005) confirms the idea according to which Scotland has implemented stricter planning as regards residential land in comparison with economic land.

Like Scotland, the Netherlands seems characterised by a more effective control of its residential urbanisation than its economic urbanisation. According to the Dutch analysts, this situation results from a predominant way of thinking that considers economic land as vital to job creation (Ploegmakers et al., 2013). In fact, this way of 
thinking leads many municipalities to develop an oversupply of economic land (van Bronkhorst, 2014).

In graph 1, the main entities of the area of analysis are positioned in relation to this area considered as a whole. It aims to compare the situation relative to the GDP standards of the economic surfaces with the situation relative to the residential surfaces, thus confirming the analyses presented above.

Graph 1. GDP standards of the economic surfaces (ES) and residential surfaces (RS) at national and intra-national level.

\section{Economic effectiveness: relationship(s) between economic land consumption and the level of development}

By taking into account all 751 NUTS 3 regions, we find statistically non-significant relationships between economic land consumption and the GDP indicators and employment numbers (with an analysis where the size effect was controlled as explained in subsection 3.3). However, if we extend the analysis by differentiating the regions per country or by taking into account the urban-rural typology, we obtain significant results that help to clarify the issue of the economic effectiveness of industrial land policies.

The calculations reveal that the relationships between economic land consumption and the level of development are statistically significant in the group of "intermediate regions" and in the group of "predominantly rural regions, close to a city". This significance is proven through both the GDP (Table 2) and employment numbers (Table 3 ). It is important to point out that the relationship is positive as regards "intermediate regions" and negative for "predominantly rural regions, close to a city". By contrast, as regards "predominantly urban regions" and "predominantly rural, remote regions", the relationships are not statistically significant.

Table 2. Parameters of the equations of regression between ES/INHAB and GDP/INHAB according to the urban-rural typology including remoteness.

Table 3. Parameters of the regression equations between ES/INHAB and EMPL/INHAB according to the urban-rural typology including remoteness.

The "predominantly urban regions" are typically characterised by the presence of a major metropolitan area. Economic specialisations might therefore explain the absence of significant relationships in these territories as they predominantly accommodate spatially intensive high value added activities in mixed urban fabrics and business districts. This observation can be linked to the subject of agglomeration economies, since such a form of economic specialisation in high value added economic sectors is determined by varied externalities such as abundant and qualified labour supply, the presence of numerous suppliers and customers, good quality infrastructures, and a high flow of information and knowledge. In such a context, our results tend to indicate that the opening of large areas to industry and services only offers economic production a marginal advantage.

On the other hand, in the "intermediate regions", offering land to companies seems to have a positive effect on GDP and employment (Graph 2). This probably has to do with the fact that these regions are well suited to the presence of businesses that require vast surfaces, like the logistics sector. However, the coefficients of regression remain 
relatively low ( 0.52 for GDP and 6.62 for employment), probably as a result of the spatially extensive nature of these types of businesses.

The analysis of Graph 2 shows a subpopulation of NUTS 3 regions for which the availability of economic land leads to a higher growth of GDP. This concerns almost exclusively western German regions. By only studying the "intermediate regions" in the western part of Germany, we obtain an $\mathrm{R}^{2}$ of 0.47 , both for the regression aimed at explaining the GDP and for the regression aimed at explaining employment numbers. In these German regions, every hectare of extra land leads to an average increase of 71.07 jobs and EUR 4.97 million of GDP.

Graph 2. Variation of GDP/INHAB according to ES/INHAB in the "intermediate regions".

Using a Chow test, it is possible to check whether the parameters of the equations of regression relative to the observations of the "intermediate regions" in the western part of Germany are statistically different from those of the equations of regression relative to all the "intermediate regions". The test rejects the parameter stability hypothesis regardless of whether we consider GDP or employment. This confirms that the western German "intermediate regions" (IR W-DE) are characterised by a statistical behaviour that differs from all the "intermediate regions" (IR).

We should also add that considering the "intermediate regions" country by country leads to significant relationships for the western part of Germany as well as for Belgium and France (Table 4). Compared with the inferred parameters for the west of Germany, the parameters are, however, far more limited for the latter two countries.

Table 4. Parameters of the equations of regression in the "intermediate regions", country by country.

As regards "predominantly rural regions, close to a city", the relationships between economic land consumption and the levels of GDP and employment are both significant and negative. This means that an increase in the consumption of land for economic activities is accompanied by a decrease in the production of wealth and employment numbers. The hypothesis that we can formulate to explain this counter-intuitive result is that, in this type of region, development agencies are offering all the more land since the region is lagging behind in terms of development. However, opening up to urbanisation does not offer the expected results in the end, thus bearing witness to the fact that the availability of land is not a sufficient condition to stimulate significant economic growth. The situation of "predominantly rural regions, close to a city" therefore points to economically ineffective land policies.

In terms of "predominantly rural, remote regions", the lack of significant relationships is primarily linked to the limited size of the population (22 observations with two atypical points). Another explanatory hypothesis is that of the absence of active land policies aimed at developing large economic estates. Unlike decision-makers in rural regions close to a city, decision-makers in the most rural regions probably have less desire to create vast economic estates. In parallel, it is important to bear in mind that our data do not take into account areas under 25 hectares, which are probably more frequent in rural regions than in other regions of Northwest Europe.

At a national and intra-national scale, the relationships between economic land consumption and levels of GDP (Table 5) are only statistically significant in the western part of Germany and in Belgium. When the calculations are conducted to explain 
employment numbers, the relationship is also significant and positive for France (Table 6). In comparison with the coefficients of regression relative to Germany (for instance, 38.40 for employment), the coefficients relating to Belgium (15.69) and France (4.19) are, however, much lower.

Table 5. Parameters of the equations of regression between ES/INHAB and GDP/INHAB per country.

Table 6. Parameters of the equations of regression between ES/INHAB and EMPL/INHAB per country.

Looking at all the NUTS 3 regions in the western part of Germany (called Kreise), the intensity of the relationship between land consumption and GDP is moderate $\left(\mathrm{R}^{2}\right.$ of 0.19). As shown in Graph 3, every hectare of extra economic land leads to an average growth in GDP of nearly EUR 2.5 million. In comparison with what was observed in Graph 2 for intermediate western German Kreise, the intensity of the relationship here is lower, confirming the special relationship between land consumption and economic development in the "intermediate regions". Taking into account employment numbers rather than GDP, the conclusions concerning the Kreise in western Germany remain unchanged. The relationship remains moderate, with an $\mathrm{R}^{2}$ of 0.24 , and every hectare of extra land is associated with almost 40 jobs. In comparison, as mentioned above, the inferred parameter for the situation of the western German "intermediate regions" alone was 71.07 jobs.

Graph 3. Variation of GDP/INHAB according to ES/INHAB in the western German Kreise.

The figures gathered in Table 6, on the relationships between land consumption and employment, also highlight the situation in the Netherlands, where the relationship is significant but negative. This represents a situation that is comparable with the one identified for "predominantly rural regions, close to a city": an increase in the consumption of land for economic activities is accompanied by a decrease in employment numbers. The well-documented case of the Netherlands highlights this result (Louw et al., 2012; Needham \& Louw, 2006; Ploegmakers et al., 2013). Land-use planning in this country takes place at a communal level. This high degree of decentralised power results in competition between municipal agencies leading to an oversupply of economic land, which is particularly prevalent in the country's regions where the economy is less dynamic - in particular the north.

\section{Discussion and conclusions}

\subsection{Methodological limitations}

We introduced this paper with the observation that, to date, the theme of industrial land has not yet been adequately addressed by regional sciences. To help fill this research gap, we have developed a pioneering piece of research on the theme of the spatial and economic effectiveness of industrial land policies. This work is based on statistical analyses relating to seven countries in Northwest Europe. Before entering into the discussion of our empirical results, it is necessary to analyse the methodological limitations of our methods of operation. The purpose of this is to envisage 
methodological improvements for further research and to help the reader to correctly interpret the results obtained.

Concerning spatial effectiveness, a key methodological issue that emerges from our methods of operation is the fact that the calculated ratio is dependent on the sectorial structures of the economy. In order to completely solve this methodological problem, it would be necessary to have data that allows jobs and added values to be situated at a very fine scale. In particular, it would be necessary to differentiate the economic activities present within economic estates from the economic activities present within mixed urban fabrics and business districts. Compared to the data currently available, this would require a much greater level of refinement in economically relevant spatial information.

As regards the theme of economic effectiveness, our methodological developments are based on univariate analyses, with land consumption as the sole explanatory variable of economic development. Of course, many other factors determine regional disparities in economic development: the intensity of the agglomeration effects, accessibility within transportation networks, the level of qualification of the manpower, R\&D expenditures, etc. In this respect, we should point out that we tested multiple regressions during our research. We finally decided to abandon this methodological approach since the information relating to the key independent variables we used overlapped with the information provided through the use of the urban-rural typology including remoteness. For our transnational approach, the same results and conclusions were therefore achieved with multiple regressions and with simple regressions. Here, we are referring in particular to the identification of three regional profiles concerning the relationships between the consumption of land for economic activities and the regions' level of development (see below the subsection 6.3). In light of this situation, we finally decided to build the article on the basis of the simplest methods possible, i.e. correlation and univariate regressions. Of course, the fact that our calculations did not justify the use of multivariate analyses does not mean that new research based on the framework we developed should not retest the opportunity to use multivariate techniques.

\subsection{Spatial effectiveness}

The spatial effectiveness of the industrial land policies was dealt with through a comparative analysis of the consumption of economic land. This analysis revealed that three countries - Ireland, Luxembourg and the United Kingdom - show very low levels of GDP standards of economic surfaces. However, it is likely that the main factor behind this situation does not correspond to industrial land policies, but rather to the specialisation of these states in tertiary sectors with a high added value. In order to verify this interpretation accurately, it would be necessary, as previously mentioned, to have data that can be used to differentiate the economic activities present within economic estates from the economic activities present within mixed urban fabrics and business districts.

In contrast with the three countries we have just mentioned, France and Belgium consume two to three times more industrial land to produce the same amount of GDP. For these two countries, such results cannot be fully explained by the effect of economic specialisations. Beyond this economic aspect, we believe it is essential to make reference to the low level of spatial effectiveness of the land policies applied in the context of mono-functional economic estates. What we see here is a situation of "economic sprawl". On the basis of the available literature, the low level of spatial effectiveness that affects both countries can be associated with low employment density in economic estates (which is synonymous with a waste in land resources) and with the 
presence of firms, in these estates, whose characteristics would have been perfectly suited to inner city neighbourhoods. Here, we are referring in particular to retail or, more generally, other service activities which, from the point of view of effective and rational planning, should preferentially be located in traditional urban fabrics.

As for the Netherlands and Germany, they occupy an intermediate position between the two abovementioned groups of countries. However, if we only consider former East Germany, the situation there is far less favourable. Here, the poor spatial efficiency measured can be explained by a relatively low level of economic development, as well as by a high consumption of industrial land inherited from Communist town planning.

\subsection{Economic effectiveness}

The analyses aimed at identifying the relationships between the consumption of land for economic activities and the regions' level of development have led to the identification of three regional profiles: the "predominantly urban regions", the "intermediate regions" and the "predominantly rural regions, close to a city". In the "predominantly urban regions", land consumption only plays a marginal role, most likely owing to the presence of numerous activities that are not very extensive spatially, yet very productive in terms of added value. By contrast, in the so-called "intermediate regions", the consumption of industrial and commercial land has a real impact on development. However, the value of the parameters obtained shows that the effective impact remains limited. Thirdly, there are the "predominantly rural regions, close to a city", where the opening of land to urbanisation does not deliver the desired results. Indeed, our results indicate that the development agencies in these regions offer all the more land since the region is lagging behind in terms of development.

Among the "intermediate regions", the western German regions stand out clearly in comparison with the regions belonging to the other territories. On the basis of the methodology developed, the most economically effective land policies are to be found in these territories. In fact, this German specificity probably results from a variety of factors combining the economic aspect and the planning aspect. From an economic point of view, Germany is a country whose industrial base remains very solid. Compared to more tertiarised economies, this situation engenders greater land needs. Concerning planning practices in Germany, we do not have any detailed information on land policies in terms of industrial development. Unfortunately, this subject is not well documented and various contacts established among German experts did not provide us with any clear explanations.

In comparison with the German case, the Dutch one is far better documented. Many publications on the subject of Dutch economic estates provide an understanding of a Dutch policy for industrial development that appears more effective spatially than economically. In terms of economic effectiveness, the Netherlands has results similar to those observed in "predominantly rural regions, close to a city", whereby an increase in the consumption of land for economic activities is accompanied by a decrease in employment numbers. On the basis of the literature, this situation can be explained by competition between municipalities, which leads to a significant oversupply of land in the regions of the country where the economy is less dynamic (van der Krabben \& Buitelaar, 2010). On the other hand, in terms of spatial effectiveness, the Dutch land policies produce better results. Compared with residential urbanisation, economic urbanisation certainly appears to be less well managed by the Dutch planners but, in comparison with the other countries taken into account, the GDP standard of economic surfaces remains limited (13.7 for the Netherlands compared to 13.9 for the whole area of analysis as mentioned in Table 1). This seems to be linked to quite high employment 
densities and, as a consequence, to a parsimonious use of ground area in economic estates.

\subsection{Policy and research implications}

This paper shows that various aspects of land policies for industrial land in Northwest Europe require readjustments. As regards spatial effectiveness, the situation in France and Belgium should be highlighted. As mentioned above, our results confirm a problem of "economic sprawl", which is challenging for the responsible authorities.

In terms of economic effectiveness, the situation is problematic in the Netherlands as well as in most "predominantly rural regions, close to a city". What we see in these contexts is land policies that ignore the evidence that the supply of land is not a sufficient condition for economic growth and job creation. Concerning the Netherlands, we also see that a decentralisation of the decision processes towards the local level can cause counter-productive competition between municipalities. There is no doubt that this situation should raise awareness in places with a trend in favour of decentralisation.

We consider that the economic effectiveness in "intermediate regions" is also challenging for the responsible authorities. Indeed, even if the statistical analyses confirm that the consumption of industrial land has a positive impact on their economic growth, this impact is actually very limited. In these regions, the release of new industrial land helps essentially in the development of activities such as logistics, which generate a limited amount of jobs and added value per surface unit. From this perspective, we question whether the economic benefit outweighs the negative impacts associated with the waste of large surface areas.

Besides policy implications for the public authorities, our empirical findings also have three major implications for a future research agenda. Firstly, we consider that our exploratory analysis focusing on Northwest Europe might provide a basis for investigations where the framework we developed would be applied to different study areas. In parallel, new research could also be developed on the countries we studied. Such new investigations could allow a more in-depth focus on a number of regional differences that we were unable to address through our transnational approach. Secondly, we also consider that our research could be usefully extended by investigating the reasons that make the western German "intermediate regions" places where land policies are particularly effective on an economic level. Thirdly, as already pinpointed, the research presented in this article could also be further developed if more detailed data were to become available on the places where employment and the production of wealth are located. This would make it possible to refine the assessment of land policies aimed at stimulating the economy through the consumption of industrial and commercial land.

\section{References}

Adams, D., Russel, L., \& Taylor-Russel, C. (1994). Land for industrial development. London: E \& FN Spon.

Alonso, W. (1964). Location and land use: toward a general theory of land rent. Cambridge, Mass.: Harvard University Press.

Baker, E. (1995). Land and property in local economic development, Local Government Studies, 21(3), 360-375.

Bramley, G., \& Kirk, K. (2005). Does planning make a difference to urban form? Recent evidence from Central Scotland, Environment and Planning A, 37(2), 355378. 
Buitelaar, E., Lagendijk, A., \& Jacobs, W. (2007). A theory of institutional change: illustrated by Dutch city-provinces and Dutch land policy, Environment and Planning A, 39(4), 891-908.

Cheshire, P.C, \& Hilber, C.A.L. (2008). Office space supply restrictions in Britain: the political economy of market revenge, The Economic Journal, 118(529), 185-221.

Cheshire, P., Leunig, T., Nathan, M., \& Overman, H. (2012). Links Between Planning and Economic Performance: Evidence Note For LSE Growth Commission. London: London School of Economics.

Costes, N. (2008). Choix de localisation des entreprises, intervention publique et efficacité urbaine: une analyse théorique et empirique de la réglementation des choix de localisation des activités de bureau en Île-de-France (Doctoral dissertation, Université de Paris 1, France). Retrieved from https://tel.archives-ouvertes.fr/tel00363846/file/Costes_Nicolas_these.pdf

D’Arcy, E., \& Keogh, G. (1997). Towards a property market paradigm of urban change, Environment and Planning A, 29(4), 685-706.

D’Arcy, E., \& Keogh, G. (1999). The Property Market and Urban Competitiveness: A Review, Urban Studies, 36(5-6), 917-928.

Deloitte \& Touche, CREAT, \& Institut wallon. (2002). Etude stratégique visant à éclairer le Gouvernement wallon en matière d'affectation d'espace à l'activité économique dans le cadre de la révision des plans de secteur. Rapport phase II, Unpublished.

Demazière, C. (2014). Localisation des activités économiques et planification spatiale en Angleterre et en France : vers un développement territorial durable ? SHS Web of Conferences, 9(04003).

EEA. (2006). Urban sprawl in Europe: the ignored challenge. EEA Report $N^{\circ} 10 / 2006$, Luxembourg: European Environment Agency.

European Commission. (2010). Investing in Europe's future. Fifth report on economic, social and territorial cohesion. Luxembourg: European Union

Fujita, M., \& Thisse, J.-F. (2000). The formation of economic agglomeration. In J.-M. Huriot \& J.-F. Thisse (Eds.), Economics of Cities: Theoretical Perspectives (3-73). Cambridge: Cambridge University Press.

Halbert, L., Henneberry, J., \& Mouzakis, F. (2014). Finance, Business Property and Urban and Regional Development, Regional Studies, 48(3), 421-424.

Halleux, J.-M., Marcinczak, S., \& van der Krabben, E. (2012). The adaptive efficiency of land use planning measured by the control of urban sprawl. The cases of the Netherlands, Belgium and Poland, Land Use Policy, 29(4), 887-898.

Henneberry, J., McGough, T., \& Mouzakis, F. (2005). Estimating the impact of planning on commercial property markets. In D. Adams, C. Watkins, \& M. White (Eds.), Planning, Public Policy \& Property Markets (103-127). Oxford: Blackwell Publishing.

Lambotte, J.-M., Girolimetto, F., Labeeuw, F.-L., \& Halleux, J.-M. (2010). Gestion des zones d'activités économiques existantes. Annexe 1 du rapport final du thème $1 \mathrm{~B}$ de la subvention 2009-2010, Namur: CPDT.

Louw, E., van der Krabben, E., \& van Amsterdam, H. (2012). The Spatial Productivity of Industrial Land, Regional Studies, 46(1), 137-147. 
Margary, F. (2012). La localisation des activités économiques et son impact sur l'étalement urbain. Les cas de Marseille, Nantes, Rennes et Tours (Doctoral dissertation, Polytech Tours, France). Retrieved from http://www.applis.univtours.fr/scd/EPU_DA/2012PFE_Margary.Francois.pdf

Martin, R. L. (2003). A study on the Factors of Regional Competitiveness, A draft final report for the European Commission Directorate-General Regional Policy. Cambridge: University of Cambridge.

Muth, R. F. (1969). Cities and housing: the spatial pattern of urban residential land use. Chicago, IL: University of Chicago Press.

Needham, B. (1995). Land for industrial development [Review of the book Land for industrial development by D. Adams, L. Russell \& C. Russell-Taylor], Town Planning Review, 66(4), 464-465.

Needham, B., \& Louw, E. (2006). Institutional Economics and Policies for Changing Land Markets: The Case of Industrial Estates in the Netherlands, Journal of Property Research, 23(1), 75-90.

OECD. (2012). Science, Technology and Industry Outlook 2012. Paris: OECD.

Ploegmakers, H., van der Krabben, E., \& Buitelaar, E. (2013). Understanding industrial land supply: how Dutch municipalities make decisions about supplying serviced building land, Journal of Property Research, 30(4), 324-344.

Rigg, J., Bebbington, A., Gough, K. V, Bryceson, D. F., Agergaard, J., Fold, N., \& Tacoli, C. (2009). The World Development Report 2009 'reshapes economic geography': geographical reflections, Transactions of the Institute for British Geographers, 34(2), 128-136.

Sellers, J. (2004). Urbanization and the Social Origins of National Policies Toward Sprawl. In H.W. Richardson \& C.-H.C. Bae (Eds.), Urban Sprawl in Western Europe and the Unites States. Aldershot: Ashgate.

Theurillat, T., Rérat, P., \& Crevoisier, O. (2014). The real estate markets: Players, institutions and territories, Urban Studies, 52(8), 1414-1433.

van Bronkhorst, B. (2014). Demand, Supply and Policy; A quantitative analysis of the business- premise and land market. The Creation of a Decision Support Tool (Doctoral dissertation, Eindhoven University of Technology, The Netherlands). Retrieved from http://www.ofcoursecme.nl/wp-content/uploads/2015/12/KENWIBBronkhorst-Bob-van1.pdf

van der Krabben, E., \& Buitelaar, E. (2010). Industrial land and property markets: market processes , market institutions and market outcomes: The Dutch case, European Planning Studies, 19(8), 2127-2146.

van der Krabben, E., \& van Dinteren, J. (2010). Public development of industrial estates in The Netherlands: undesired market outcomes and policy interventions, Tijdschrift voor economische en sociale geografie, 101(1), 91-99.

Vandermeer, M.-C., \& Halleux, J.-M. (2013). Le rôle de l'immobilier d'entreprise dans la compétitivité des territoires: le cas de la Wallonie, URBIA - Les Cahiers Du Développement Urbain Durable, Special edition, 67-80. 
Table 1. Average consumption of economic surfaces to produce EUR 100 million of GDP, standard deviation and coefficient of variation in 2006.

\begin{tabular}{lccc}
\hline Country & Average (ha) & Standard deviation & Coefficient of variation \\
\hline Ireland & 5.4 & 1.9 & 0.35 \\
Luxembourg & 8.1 & - & - \\
United Kingdom & 9.0 & 8.8 & 0.98 \\
Netherlands & 13.7 & 7.9 & 0.58 \\
7 countries & 13.9 & 12.5 & 0.90 \\
Germany & 14.3 & 14.2 & 0.99 \\
$\quad$ West DE & 11.7 & 6.3 & 0.54 \\
East $D E$ & 28.8 & 16.8 & 0.58 \\
Belgium & 16.6 & 9.6 & 0.58 \\
France & 19.3 & 7.4 & 0.38 \\
\hline
\end{tabular}

Source: authors' calculation based on Eurostat (2006) and EEA (2006) data

Table 2. Parameters of the equations of regression between the ES/INHAB and the GDP/INHAB according to the urban-rural typology including remoteness.

\begin{tabular}{|c|c|c|c|c|c|}
\hline $\begin{array}{c}\text { Parameters of equations of regression } \\
\text { between ES/INHAB and GDP/INHAB } \\
\text { NUTS } 3 \text { scale - } 2006\end{array}$ & $\begin{array}{l}\text { No. of } \\
\text { atypical } \\
\text { points }\end{array}$ & $\begin{array}{c}\text { R - Coeff. } \\
\text { of corr. }\end{array}$ & $\begin{array}{l}\mathrm{R}^{2}- \\
\text { Coeff. of } \\
\text { det. }\end{array}$ & $\begin{array}{c}\text { b - Coeff. } \\
\text { of regr. }\end{array}$ & $\begin{array}{c}\mathrm{p}- \\
\text { value }\end{array}$ \\
\hline Predominantly urban regions $(n=218)$ & 8 & 0.01 & 0.00 & 0.05 & 0.88 \\
\hline Intermediate regions $(n=307)$ & 2 & 0.15 & 0.02 & 0.52 & 0.01 \\
\hline $\begin{array}{l}\text { Predominantly rural regions, close to a } \\
\text { city }(n=177)\end{array}$ & 10 & 0.17 & 0.03 & -0.28 & 0.02 \\
\hline $\begin{array}{l}\text { Predominantly rural, remote regions }(\mathrm{n}= \\
\text { 24) }\end{array}$ & 0 & 0.18 & 0.03 & -0.28 & 0.41 \\
\hline
\end{tabular}

Source: authors' calculation based on Eurostat (2006) and EEA (2006) data

Observations whose absolute value of the residuals was twice as high as the standard deviation were considered as atypical.

Significance threshold at 0.05 .

Table 3. Parameters of the regression equations between the ES/INHAB and EMPL/INHAB according to the urban-rural typology including remoteness.

\begin{tabular}{lccccc}
\hline $\begin{array}{c}\text { Parameters of equations of regression } \\
\text { between ES/INHAB and the EMPL/INHAB } \\
\text { NUTS 3 scale - 2006 }\end{array}$ & $\begin{array}{c}\text { No. of } \\
\text { atypical } \\
\text { points }\end{array}$ & $\begin{array}{c}\mathrm{R} \text { - Coeff. } \\
\text { of corr. }\end{array}$ & $\begin{array}{c}\mathrm{R}^{2}- \\
\text { Coeff. of } \\
\text { det. }\end{array}$ & $\begin{array}{c}\text { b - Coeff. } \\
\text { of regr. }\end{array}$ & $\begin{array}{c}\mathrm{p} \text { - } \\
\text { value }\end{array}$ \\
\hline $\begin{array}{l}\text { Predominantly urban regions }(\mathrm{n}=218) \\
\text { Intermediate regions }(\mathrm{n}=307)\end{array}$ & 2 & 0.05 & 0.00 & 3.29 & 0.41 \\
$\begin{array}{l}\text { Predominantly rural regions, close to } \mathrm{a} \\
\text { city }(\mathrm{n}=177)\end{array}$ & 12 & 0.19 & 0.03 & -4.09 & $\mathbf{0 . 0 1}$ \\
$\begin{array}{l}\text { Predominantly rural, remote regions }(\mathrm{n}= \\
\text { 24) }\end{array}$ & 2 & 0.30 & 0.09 & 8.08 & 0.18 \\
\hline
\end{tabular}

Source: authors' calculation based on Eurostat (2006) and EEA (2006) data

Observations whose absolute value of the residuals was twice as high as the standard deviation were considered as atypical.

Significance threshold at 0.05 . 
Table 4. Parameters of the equations of regression in the "intermediate regions", country by country.

\begin{tabular}{llllll}
\hline $\begin{array}{c}\text { Parameters of the equations of } \\
\text { regression in the IR } \\
\text { NUTS 3 scale - 2006 }\end{array}$ & & $\mathrm{R}$ & $\mathrm{R}^{2}$ & $\begin{array}{c}\mathrm{b} \text { - Coeff. } \\
\text { of regr. }\end{array}$ & $\mathrm{p}$-value \\
\hline GDP/INHAB according to & Belgium $(\mathrm{n}=12)$ & 0.74 & 0.55 & 2.23 & $\mathbf{0 . 0 1}$ \\
ES/INHAB & W-DE $(\mathrm{n}=138)$ & 0.68 & 0.47 & 4.97 & $\mathbf{0 . 0 0}$ \\
& France $(\mathrm{n}=29)$ & 0.43 & 0.18 & 0.83 & $\mathbf{0 . 0 2}$ \\
EMPL/INHAB according to & Belgium $(\mathrm{n}=12)$ & 0.76 & 0.58 & 20.69 & $\mathbf{0 . 0 0}$ \\
ES/INHAB & W-DE $(\mathrm{n}=138)$ & 0.67 & 0.47 & 71.07 & $\mathbf{0 . 0 0}$ \\
& France $(\mathrm{n}=29)$ & 0.49 & 0,24 & 10.13 & $\mathbf{0 . 0 1}$ \\
\hline
\end{tabular}

Source: authors' calculation based on Eurostat (2006) and EEA (2006) data

Observations whose absolute value of the residuals was twice as high as the standard deviation were considered as atypical.

Significance threshold at 0.05 .

Table 5. Parameters of the equations of regression between the ES/INHAB and GDP/INHAB per country.

\begin{tabular}{lccccc}
\hline $\begin{array}{c}\text { Parameters of the equations of } \\
\text { regression between the ES/INHAB } \\
\text { and the GDP/INHAB } \\
\text { NUTS 3 scale - 2006 }\end{array}$ & $\begin{array}{c}\text { No. of } \\
\text { atypical } \\
\text { points }\end{array}$ & $\begin{array}{c}\mathrm{R} \text { - Coeff. } \\
\text { of corr. }\end{array}$ & $\begin{array}{c}\mathrm{R}^{2} \text { - } \\
\text { Coeff. of } \\
\text { det. }\end{array}$ & $\begin{array}{c}\mathrm{b} \text { - Coeff. } \\
\text { of regr. }\end{array}$ & $\begin{array}{c}\mathrm{p}- \\
\text { value }\end{array}$ \\
\hline Germany $(\mathrm{n}=410)$ & 19 & 0.01 & 0.00 & 0.02 & 0.89 \\
$\quad W-D E(n=326)$ & 0 & 0.44 & 0.19 & 2.46 & $\mathbf{0 . 0 0}$ \\
$E-D E(n=103)$ & 0 & 0.10 & 0.01 & 0.15 & 0.31 \\
Belgium $(\mathrm{n}=43)$ & 1 & 0.40 & 0.16 & 1.14 & $\mathbf{0 . 0 1}$ \\
France $(\mathrm{n}=94)$ & 2 & 0.08 & 0.01 & 0.19 & 0.41 \\
Ireland $(\mathrm{n}=8)$ & $/$ & 0.54 & 0.29 & 7.09 & 0.17 \\
Netherlands $(\mathrm{n}=38)$ & 2 & 0.03 & 0.00 & 0.07 & 0.85 \\
United Kingdom $(\mathrm{n}=124)$ & 4 & 0.04 & 0.00 & 0.15 & 0.66 \\
\hline
\end{tabular}

Source: authors' calculation based on Eurostat (2006) and EEA (2006) data

Observations whose absolute value of the residuals was twice as high as the standard deviation were considered as atypical.

Significance threshold at 0.05 . 
Table 6. Parameters of the equations of regression between the ES/INHAB and EMPL/INHAB per country.

\begin{tabular}{lccccc}
\hline $\begin{array}{c}\text { Parameters of the equations of } \\
\text { regression between the ES/INHAB } \\
\text { and the EMPL/INHAB }\end{array}$ & $\begin{array}{c}\text { No. of } \\
\text { atypical } \\
\text { points }\end{array}$ & $\begin{array}{c}\mathrm{R} \text { - Coeff. } \\
\text { of corr. }\end{array}$ & $\begin{array}{c}\mathrm{R}^{2}- \\
\text { Coeff. of } \\
\text { det. }\end{array}$ & $\begin{array}{c}\text { b - Coeff. } \\
\text { of regr. }\end{array}$ & $\begin{array}{c}\mathrm{p} \text { - } \\
\text { value }\end{array}$ \\
\hline Germany $(\mathrm{n}=399)$ & 30 & 0.11 & 0.01 & 4.20 & $\mathbf{0 . 0 2}$ \\
$W-D E(n=326)$ & 0 & 0.49 & 0.24 & 38.40 & $\mathbf{0 . 0 0}$ \\
$E-D E(n=103)$ & 0 & 0.10 & 0.01 & -2.73 & 0.40 \\
Belgium $(\mathrm{n}=43)$ & 1 & 0.52 & 0.27 & 15.69 & $\mathbf{0 . 0 0}$ \\
France $(\mathrm{n}=94)$ & 2 & 0.22 & 0.05 & 4.19 & $\mathbf{0 . 0 4}$ \\
Ireland $(\mathrm{n}=8)$ & $/$ & 0.28 & 0.08 & 108.70 & 0.51 \\
Netherlands $(\mathrm{n}=36)$ & 4 & 0.33 & 0.11 & -5.93 & $\mathbf{0 . 0 5}$ \\
United Kingdom $(\mathrm{n}=123)$ & 5 & 0.15 & 0.02 & 4.88 & 0.10 \\
\hline
\end{tabular}

Source: authors' calculation based on Eurostat (2006) and EEA (2006) data

Observations whose absolute value of the residuals was twice as high as the standard deviation were considered as atypical.

Significance threshold at 0.05 . 
Map 2. The NUTS 3 regions according to the urban-rural typology including remoteness.
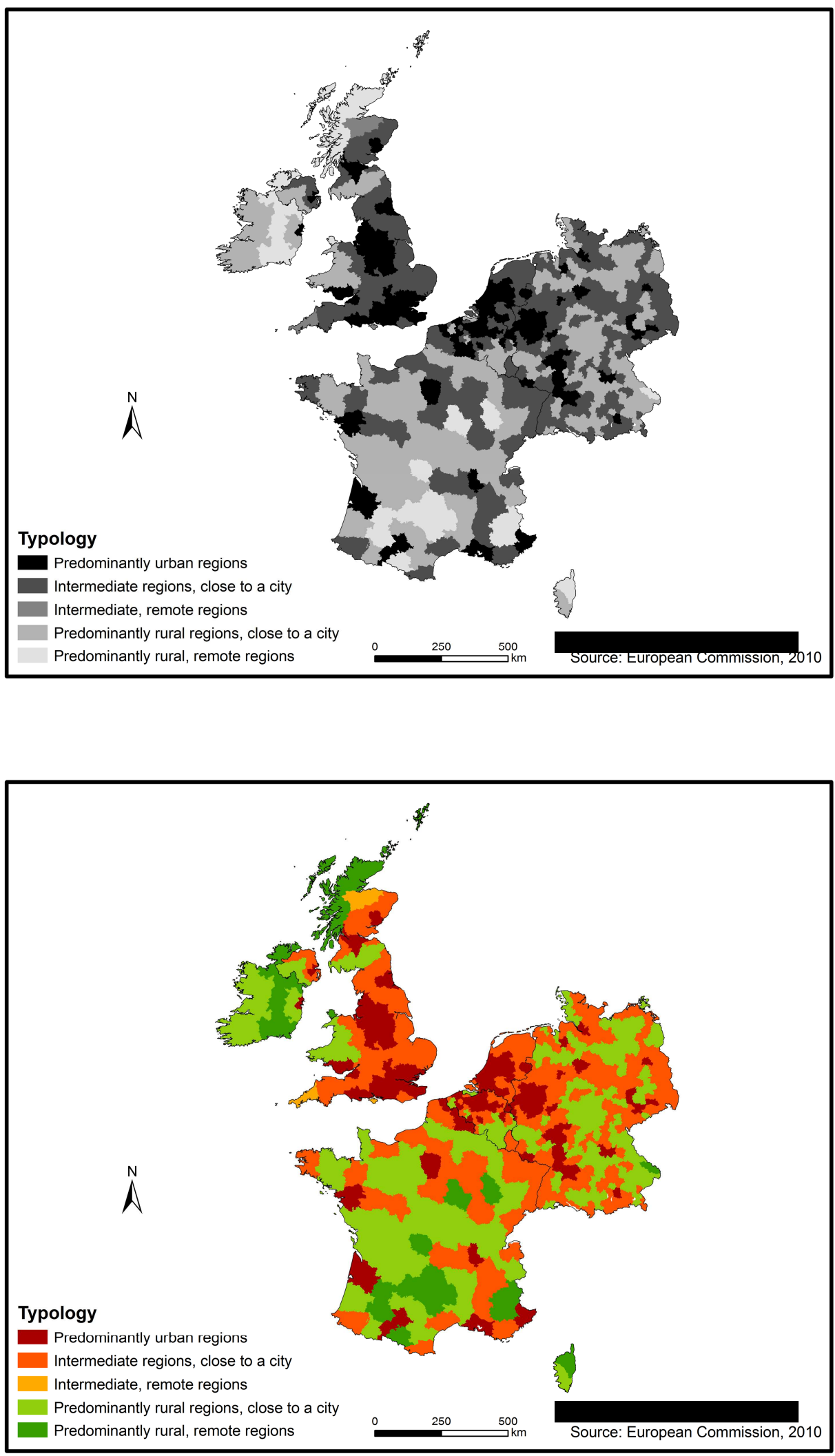
Map 2. The GDP standards of economic surfaces (2006).

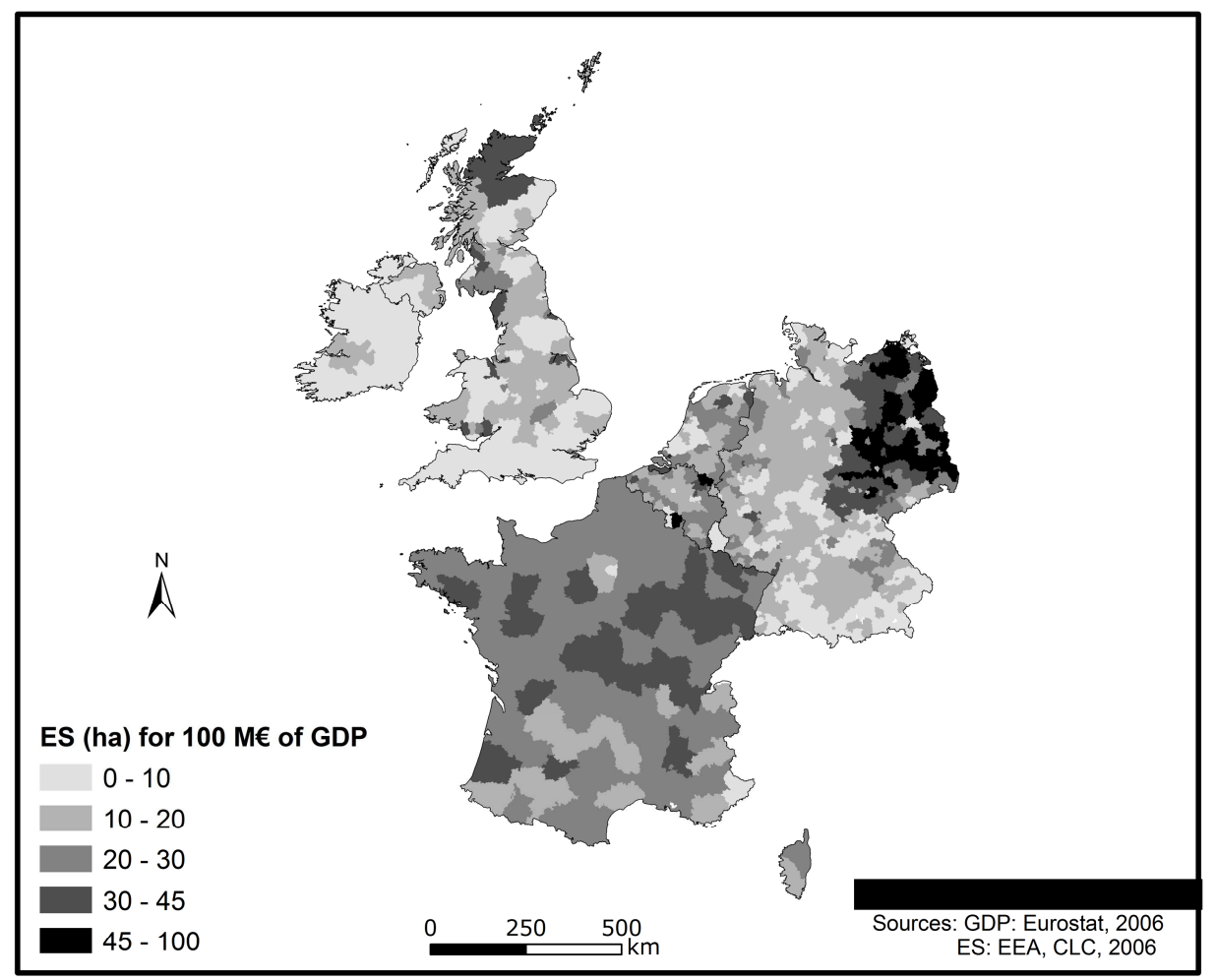

ES (ha) for $100 \mathrm{M} €$ of GDP

$0-10$

$10-20$

$20-30$

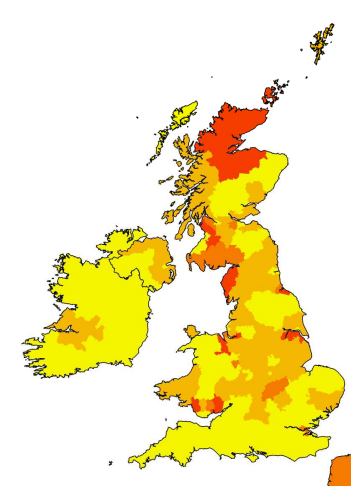

$\stackrel{N}{\Lambda}$

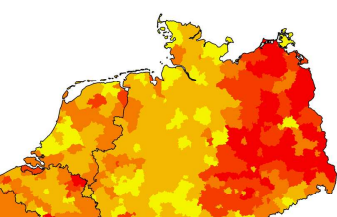

$30-45$

$45-100$

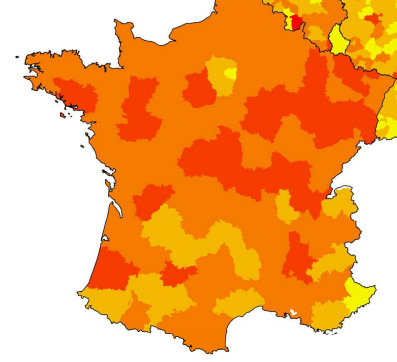

$0 \quad 250 \quad 500$

Sources: GDP: Eurostat, 2006
ES: EEA, CLC, 2006 
Map 3. The GDP standards of residential surfaces (2006).
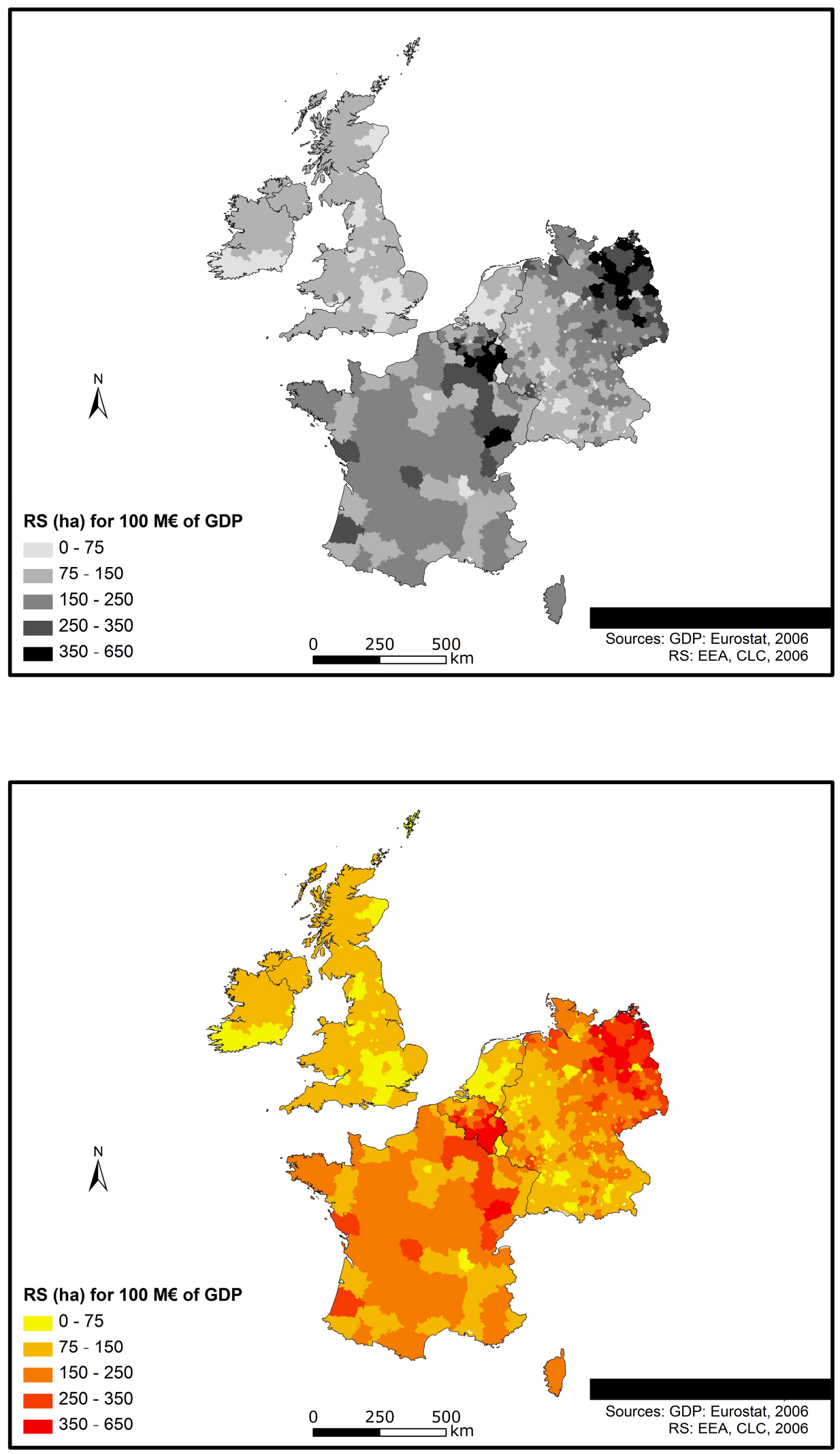
Graph 1. GDP standards of the economic surfaces (ES) and residential surfaces (RS) at national and intra-national level.

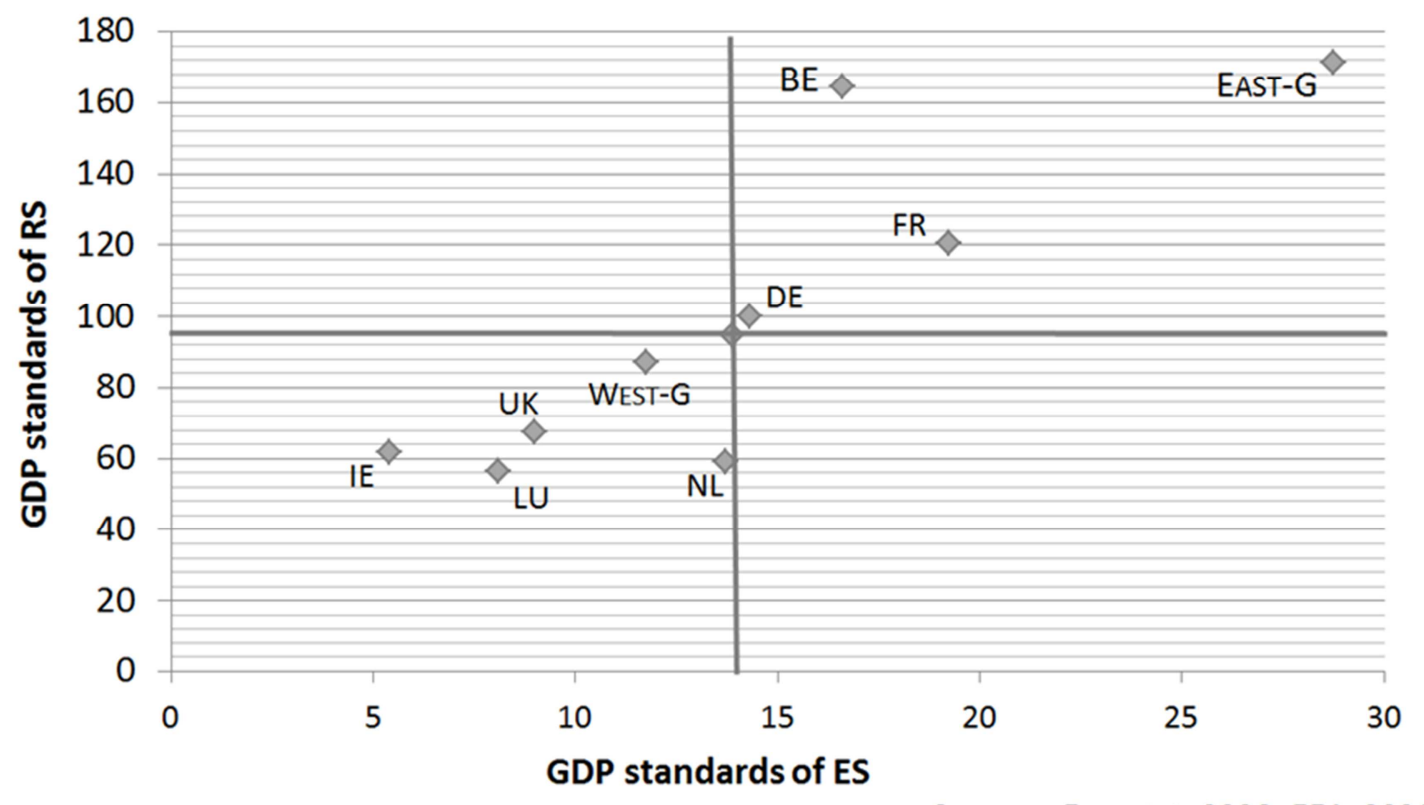

Graph 2. Variation of the GDP/INHAB according to the ES/INHAB in the "intermediate regions".

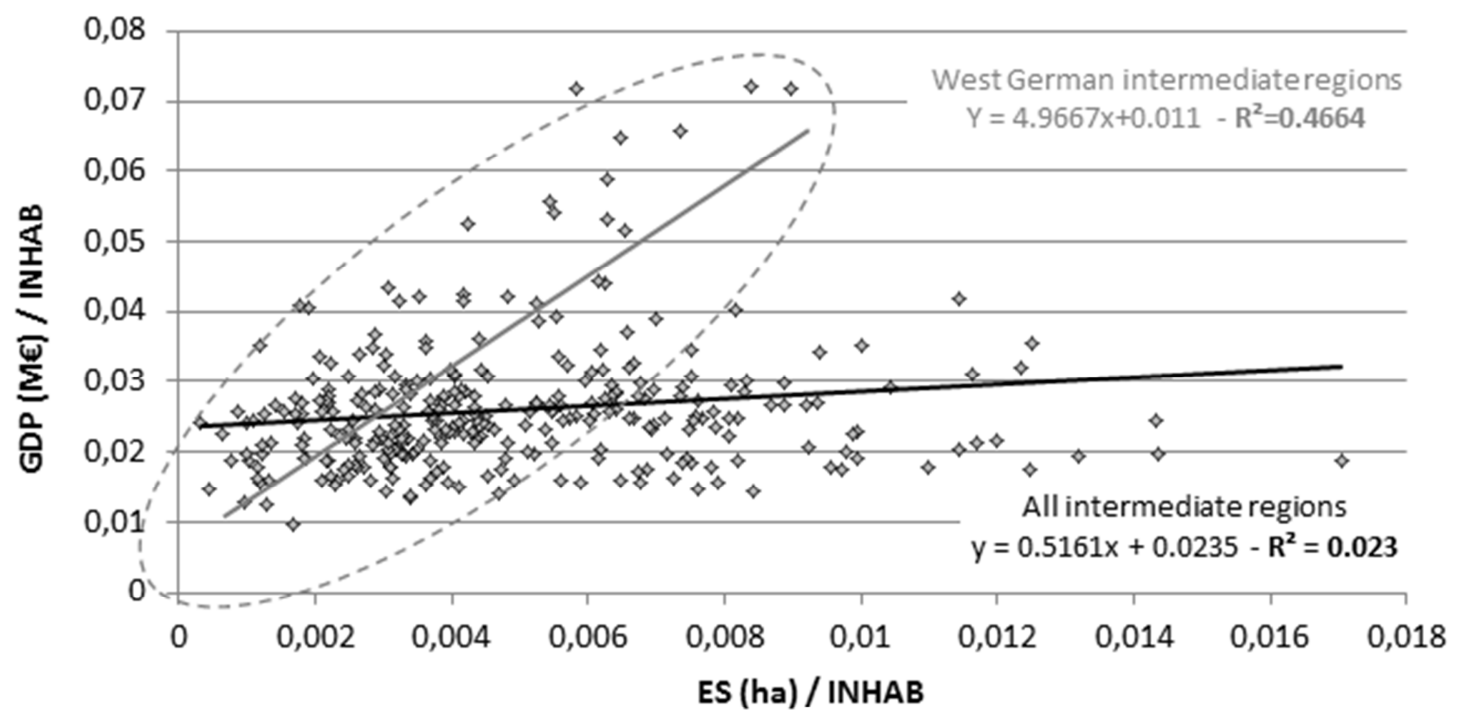

Sources: Eurostat, 2006; EEA, 2006 
Graph 3. Variation of the GDP/INHAB according to the ES/INHAB in the western German Kreise.

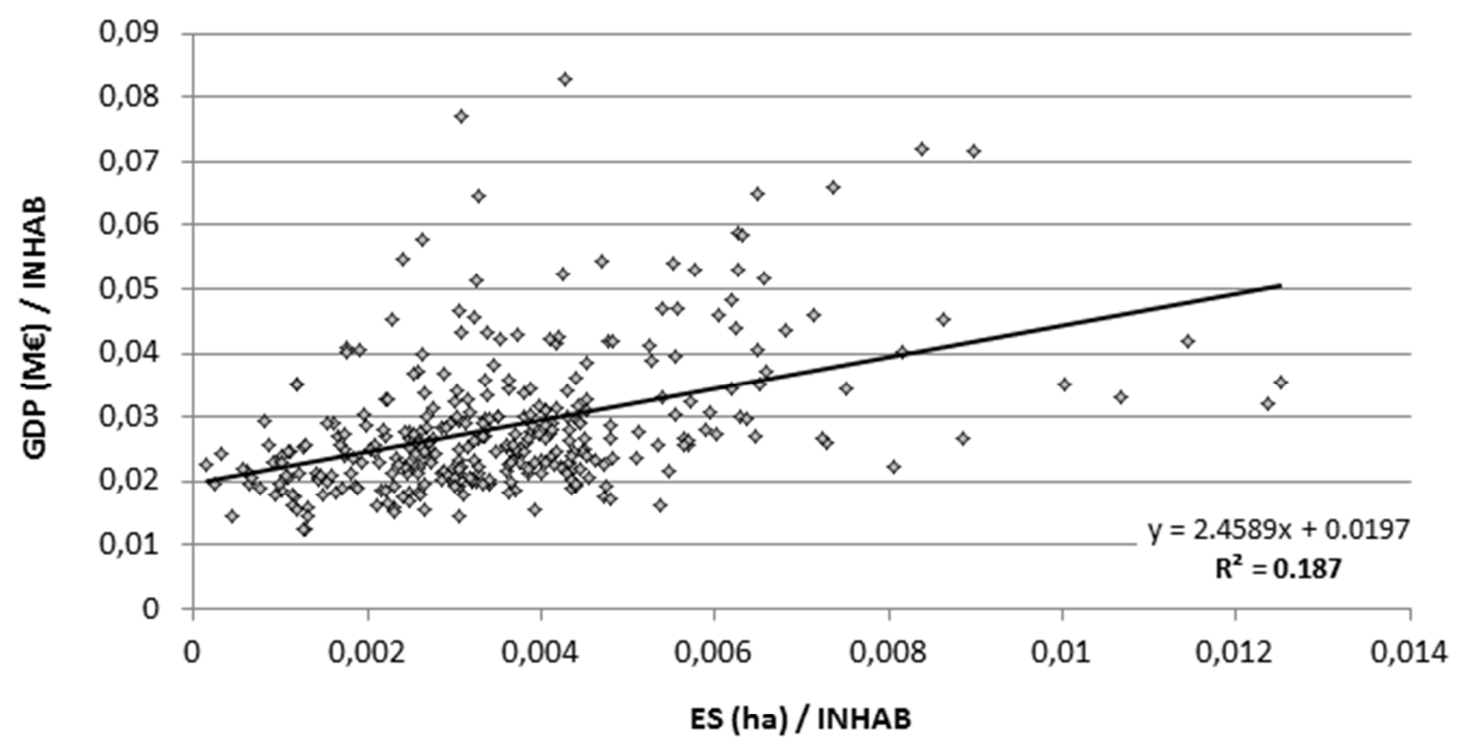

Sources: Eurostat, 2006; EEA, 2006 